OCCUPATIONAL LUNG DISEASE

\title{
Respiratory health status of Australian veterans of the 1991 Gulf War and the effects of exposure to oil fire smoke and dust storms
}

\author{
H L Kelsall, M R Sim, A B Forbes, D P McKenzie, D C Glass, J F Ikin, P Ittak, M J Abramson
}

Thorax 2004;59:897-903. doi: 10.1136/thx.2003.017103

See end of article for authors' affiliations

Correspondence to: Dr H Kelsall, Department of Epidemiology and Preventive Medicine, Monash University-Central and Eastern Clinical School, Alfred Hospital, Commercial Road, Melbourne, Victoria 3004, Australia; helen.kelsall@ med.monash.edu.au

Received 8 October 2003 Accepted 8 July 2004

\begin{abstract}
Background: Since the 1991 Gulf War concerns have been raised about the effects on veterans' health of exposures to Kuwaiti oil fire smoke and to dust storms.

Methods: A cross sectional study compared 1456 Australian Gulf War veterans with a randomly sampled military comparison group $(n=1588)$. A postal questionnaire asked about respiratory conditions, exposures, medications, tobacco use, demographic characteristics, and military service details. During a medical assessment, spirometric tests and a physical examination were performed and a respiratory questionnaire was administered.

Results: The response rate for the Gulf War veteran group was $80.5 \%$ and for the comparison group $56.8 \%$. Australian Gulf War veterans had a higher than expected prevalence of respiratory symptoms and respiratory conditions suggesting asthma (OR 1.4; $95 \% \mathrm{Cl} 1.1$ to 1.9) and bronchitis first diagnosed since the Gulf War (OR 1.9; $95 \% \mathrm{Cl} 1.2$ to 3.1 ) but did not have poorer lung function or more ventilatory abnormalities than the comparison group. Veterans who reported exposure to oil fire smoke had slightly poorer forced vital capacity (difference between means -0.10 ; $95 \% \mathrm{Cl}-0.18$ to -0.03 ) and those exposed to dust storms had a slightly better peak expiratory flow rate (difference between means $12.0 \mathrm{l}$ / $\mathrm{min} ; 95 \% \mathrm{Cl} 0.6$ to 23.4) than veterans who did not report exposure. Veterans who were in the Gulf at or after the start of the oil fires had more respiratory conditions suggesting asthma (OR $1.7 ; 95 \% \mathrm{Cl} 1.0$ to 2.9) than those who completed their deployment before this time.

Conclusions: Increased self-reporting of respiratory symptoms, asthma, and bronchitis by veterans was not reflected in poorer lung function. The findings do not suggest major long term sequelae of exposure to oil fire smoke or dust storms.
\end{abstract}

by veterans in postal or telephone surveys ${ }^{10-12}$ and "diseases of the respiratory system" has been a relatively common diagnosis in self-referred veteran populations in registry studies. ${ }^{13}$ There has been very limited objective evaluation of respiratory function in veterans using spirometric tests ${ }^{14} 15$ and none in the larger cross sectional studies of representative populations. ${ }^{10-12} 16$

Australia deployed 1871 defence personnel to the Gulf area as part of a larger multinational response to the invasion of Kuwait by Iraq on 2 August 1990. We aimed to investigate whether Australian veterans had a higher than expected prevalence of respiratory symptoms and respiratory conditions and poorer lung function. We also investigated whether veterans who reported exposure to SMOIL or to dust storms, or who were in the Gulf at or after the start of the air war, had more respiratory conditions and poorer lung function than those who did not report exposure or who completed their deployment before this time.

\section{METHODS}

\section{Study population}

The study population comprised the entire cohort of 1871 Australian veterans (1833 men, 38 women) who had served in the Gulf region during the period from 2 August 1990 to 4 September 1991 (1579 Navy, 123 Army, 169 Air Force personnel). A comparison group of 2924 subjects (2850 men, 74 women) was randomly selected from 26411

Abbreviations: $\mathrm{FEV}_{1}$, forced expiratory volume in 1 second; FVC, forced vital capacity; PEFR, peak expiratory flow rate; SMOIL, smoke from burning oil wells medical conditions have been more commonly self-reported 
Australian Defence Force personnel who were in operational units at the time of the Gulf War but were not deployed to that conflict. The comparison group was frequency matched to the veteran group by sex, service type, and three-year age bands, and additionally by officer/non-officer status within the Army subgroup and by aircrew/non-aircrew status within the Air Force subgroup. The study was conducted from August 2000 to April 2002. Subjects were recruited via mailed invitation with two further mailings and follow up telephone contact for non-responders.

Overall, from the 1808 eligible veterans (not deceased or living overseas for the duration of the study) and 2796 eligible comparison group subjects, 1456 (80.5\%) veterans and 1588 (56.8\%) comparison group subjects participated, as described previously. ${ }^{17}$

The human research ethics committees of Monash University, Department of Veterans' Affairs, and the Department of Defence approved the study.

\section{Data collection}

Participants completed a self-administered postal questionnaire which included questions about demographic and military service details, cigarette smoking and tobacco use, doctor diagnosed or treated medical conditions including the year first diagnosed, current use of medicine, exposure to dust storms and intense smoke and use of a respirator during active military deployments, and the period of time in contact with SMOIL during the Gulf War deployment.

Participants undertook a health assessment at one of 10 medical clinics located around Australia. Respiratory symptoms and conditions were assessed using a questionnaire based on the European Community Respiratory Health Survey (ECRHS) ${ }^{18}$ and the American Thoracic Society (ATS) questionnaires. ${ }^{19}$ Height and weight were measured using a stadiometer and Tanita Body Composition Analyzers TBF410, respectively. Maximal forced expiratory measurements were obtained using the flow sensing QRS SpiroCard spirometers ${ }^{20}$ with Office Medic software (QRS Diagnostic, Plymouth, MN, USA) according to recommended ATS procedures. ${ }^{21}$ Skin prick testing was conducted with standardised house dust mite, grass mix, cat dander and mould mix allergen extracts, negative and positive controls.

The respiratory system was examined for pharyngitis, tonsillar enlargement and/or inflammation or absence, respiratory rate, chest deformity, wheeze on auscultation, and other abnormalities. The doctor also asked about selfreported doctor diagnosed or treated asthma and bronchitis in the postal questionnaire and classified the likelihood of diagnosis as "non-medical", "unlikely", "possible" or "probable". This was done to improve the accuracy of classification of these self-reported diagnoses.

Asthma ever was defined as a positive response to the question: "Have you ever had asthma?" Doctor diagnosed asthma was defined as asthma that had been confirmed by a doctor. ${ }^{18}$ The ECRHS definition suggesting asthma was an attack of asthma or being woken by an attack of shortness of breath at any time in the previous 12 months or current use of asthma medication. ${ }^{18}$ Air flow limitation was defined physiologically as forced expiratory volume in l second/ forced vital capacity $\left(\mathrm{FEV}_{\mathrm{l}} / \mathrm{FVC}\right)<70 \%{ }^{22}$ Doctor diagnosed chronic bronchitis was defined as a positive response to the questions: "Have you ever had chronic bronchitis?" and "Was this confirmed by a doctor?"19 Chronic obstructive bronchitis was defined as cough for as long as 3 months in each of the past 2 years and $\mathrm{FEV}_{1} / \mathrm{FVC}<70 \% .{ }^{22}{ }^{23}$ A working definition of emphysema was doctor diagnosed emphysema ever, or shortness of breath when hurrying on level ground or walking up a slight hill and either shortness of breath walking with other people of your own age or having to stop for breath when walking at your own pace on level ground, or $\mathrm{FEV}_{1} / \mathrm{FVC}<70 \%$.

Atopy was defined as a positive response on skin prick testing (mean wheal diameter of allergen solution at least $3 \mathrm{~mm}$ greater than that of negative control) ${ }^{24}$ to one or more allergen extracts. Pack years of cigarette consumption (assuming 20 cigarettes per pack) were based on the reported average quantity of cigarettes, tobacco or cigars smoked per day, and duration of smoking in years.

Ventilatory function in participants was classified as "no abnormality" (FVC $\geqslant 80 \%$ predicted and $\mathrm{FEV}_{\mathrm{l}} / \mathrm{FVC} \% \geqslant 70 \%$ ) or an "obstructive" $\left(\mathrm{FEV}_{\mathrm{l}} / \mathrm{FVC} \%<70 \%\right.$ and $\mathrm{FVC} \geqslant 80 \%$ predicted), "restrictive" (FVC $<80 \%$ predicted and $\mathrm{FEV}_{\mathrm{l}} /$ FVC $\% \geqslant 70 \%$ ) or "mixed" (FVC $<80 \%$ predicted and $\mathrm{FEV}_{1} /$ FVC\% $<70 \%)$ ventilatory defect. ${ }^{25}$

\section{Statistical analysis}

Statistical analyses were performed using Stata version 7.0. ${ }^{26}$ Associations between deployment and symptoms/medical conditions, adjusted for potential confounding factors (age (linear term), height (linear term), smoking $(0,<10,10-20$, $>20$ pack years), weight, atopy, branch of service, rank, highest education level and marital status) using logistic regression were reported as adjusted prevalence odds ratios (ORs) with 95\% confidence intervals (95\% CI). Predicted values of lung function were calculated using multiple regression equations for peak expiratory flow rate $(\mathrm{PEFR})^{27}$ and other lung function indices. ${ }^{28}$ Differences in the mean values of lung function indices between study groups, adjusting for potential confounding factors (as listed above), were obtained using robust linear regression. ${ }^{29}$ Exposureresponse trends were computed using SMOIL exposure as a categorical variable in the regressions.

To investigate the possible effects of participation bias on our results, we collected brief demographic and 12 item Short Form Health Survey (SF-12) ${ }^{30}{ }^{31}$ data from a telephone survey of non-participants. Study participants who completed the postal questionnaire also completed the SF-12. A prediction model was used to compute an age, rank, and service adjusted odds ratio for the relative health outcome of doctor diagnosed asthma in Gulf War veterans versus comparison group subjects as if the study had achieved full participation. The predicted "full participation" adjusted ORs were averaged over 100 replications of the analyses. ${ }^{17}$

\section{RESULTS}

\section{Demographic data, atopy and smoking}

Because of the very small numbers of female veterans, the analyses were limited to male subjects: 1424 veterans (1232 Navy, 87 Army, 105 Air Force) and 1548 in the comparison group (1123 Navy, 172 Army, 253 Air Force). Veterans were slightly younger, more likely to have served in the Navy, were less highly ranked, and less likely to have tertiary education than comparison group subjects. ${ }^{17}$ A similar proportion of veterans and comparison group were defined as atopic $(52.3 \% \vee 52.6 \%)$ and were categorised as current $(25.9 \% v$ $23.0 \%$ ), former (30.4\% v 32.2\%), or never/occasional (43.5\% v $44.6 \%)$ smokers. Veteran current and former smokers smoked less than current (mean $18.5 \vee 21.6$ pack years) and former (12.6 $v 14.9$ pack years) smokers in the comparison group.

\section{Respiratory symptoms and conditions}

Veterans reported all respiratory symptoms more commonly than did the comparison group (table 1) and the results were statistically significant for all symptoms except morning cough and sputum.

We used several definitions to compare asthma, air flow limitation, chronic bronchitis and emphysema between study 
Table 1 Prevalence and odds ratios (ORs) of respiratory symptoms in the previous 12 months

\begin{tabular}{lllll}
\hline Respiratory symptoms & $\begin{array}{l}\text { Gulf War } \\
\text { veterans } \\
\mathbf{n}(\%)\end{array}$ & $\begin{array}{l}\text { Comparison } \\
\text { group } \\
\mathbf{n}(\%)\end{array}$ & $\begin{array}{l}\text { Adjusted } \\
\text { OR }^{*}\end{array}$ & $\mathbf{9 5 \% ~ C l}$ \\
\hline Wheeze only & $345(24.9)$ & $259(18.8)$ & 1.4 & 1.2 to 1.7 \\
Wheeze when no cold & $228(16.6)$ & $152(11.1)$ & 1.6 & 1.3 to 2.0 \\
Wheeze with breathlessness & $171(12.4)$ & $99(7.2)$ & 1.8 & 1.3 to 2.3 \\
Nocturnal chest tightness & $191(13.9)$ & $137(10.0)$ & 1.4 & 1.1 to 1.9 \\
Nocturnal cough & $337(24.3)$ & $250(18.1)$ & 1.4 & 1.1 to 1.7 \\
Morning cough & $144(10.4)$ & $121(8.8)$ & 1.2 & 0.9 to 1.5 \\
Day or night time cough & $206(14.9)$ & $157(11.4)$ & 1.3 & 1.0 to 1.6 \\
Morning sputum & $211(15.3)$ & $172(12.5)$ & 1.2 & 1.0 to 1.5 \\
Spontaneous dyspnoea & $106(7.7)$ & $66(4.8)$ & 1.6 & 1.1 to 2.2 \\
Post-exertional dyspnoea & $297(21.6)$ & $231(16.8)$ & 1.3 & 1.1 to 1.6 \\
Nocturnal dyspnoea & $78(5.6)$ & $51(3.7)$ & 1.5 & 1.0 to 2.2 \\
\hline *Odds ratios are adjusted for age, height, smoking, weight, atopy, education, marital status, service, and rank.
\end{tabular}

groups. Table 2 shows that veterans reported more asthma than the comparison group using the ECRHS definition suggesting asthma and significantly more bronchitis that had first been diagnosed since the Gulf War and rated as a possible or probable diagnosis, but there were no differences between the groups based on alternative definitions or for emphysema.

The risks of respiratory symptoms and conditions across subgroups of service type, age and rank at the time of deployment were also examined. The reporting of wheeze in veterans compared with the comparison group varied across service types and was greatest in the Army (Navy adjusted OR 1.3 (95\% CI 1.0 to 1.6); Army adjusted OR 2.9 (95\% CI 1.5 to 5.7); Air Force adjusted OR 2.1 (95\% CI 1.0 to 4.2); p value for interaction $=0.040$ ). Similarly, the reporting of morning sputum in veterans compared with the comparison group varied across ranks and was lowest in officers (Officer adjusted OR 0.5 (95\% CI 0.3 to 1.0); other ranks-supervisory adjusted OR 1.4 (95\% CI 1.0 to 1.9 ); other ranks-non supervisory adjusted OR 1.5 (95\% CI 1.0 to 2.2 ); p value for interaction $=0.022$ ). There were no differences in the risk of respiratory symptoms with age or in the risk of respiratory conditions with service type, age, or rank.

\section{Lung function and ventilatory abnormalities}

Spirometric tests were completed by 1341 veterans and 1340 comparison group subjects. ATS criteria were used to decide which spirometric data to include in the analysis. ${ }^{21}$ A slightly lower proportion of veterans than the comparison group met the ATS criteria overall $(79.8 \% v 82.9 \%)$ and the reproducibility criteria for FVC $(82.0 \% v 85.4 \%)$ and $\mathrm{FEV}_{1}(85.3 \% v$ $88.5 \%)$.

Table 3 shows the lung function indices compared between study groups. The lung function of veterans and the comparison group was very similar. The slightly greater $\mathrm{FEV}_{1} / \mathrm{FVC} \%$, mean $\mathrm{FEF}_{75 \%}$ and mean $\mathrm{FEF}_{25-75 \%}$ in veterans were not considered to be clinically important differences. There were no differences in the risk of impaired flow indices or volumes across subgroups of age, service type, or rank (data not shown).

The majority of individuals in both study groups did not have any ventilatory abnormality (90.7\% veterans $v 89.6 \%$ comparison group). Similar proportions of veterans and comparison group subjects had obstructive $(6.4 \% \vee 8.2 \%$, adjusted OR 0.8 (95\% CI 0.6 to 1.1$)$ ), restrictive (3.1\% v 2.3\%, adjusted OR 1.5 (95\% CI 0.8 to 2.6$)$ ), or mixed ( $0.2 \% v 0.4 \%$, adjusted OR 0.7 (95\% CI 0.1 to 4.2$)$ ) ventilatory defects, respectively.

In our analyses we have maximised the use of available data so the denominators may vary slightly. In order to assess whether differences between overall results for self-reported respiratory symptoms and respiratory conditions and spirometry were due to the different numbers of subjects included in each analysis, we re-analysed the respiratory symptoms

Table 2 Prevalence and odds ratios (ORs) of respiratory conditions

\begin{tabular}{|c|c|c|c|c|}
\hline Respiratory condition & $\begin{array}{l}\text { Gulf War } \\
\text { veterans } \\
\text { n }(\%)\end{array}$ & $\begin{array}{l}\text { Comparison } \\
\text { group } \\
\text { n (\%) }\end{array}$ & $\begin{array}{l}\text { Adjusted } \\
\text { OR }^{*}\end{array}$ & $95 \% \mathrm{Cl}$ \\
\hline \multicolumn{5}{|l|}{ Asthma } \\
\hline Asthma ever & 190 (13.7) & $162(11.8)$ & 1.2 & 0.9 to 1.5 \\
\hline Doctor diagnosed asthma & 165 (12.0) & $141(10.3)$ & 1.2 & 0.9 to 1.5 \\
\hline Current use of asthma medication & $59(4.3)$ & $44(3.2)$ & 1.4 & 0.9 to 2.2 \\
\hline ECRHS definition suggesting asthma & $141(10.2)$ & $102(7.5)$ & 1.4 & 1.1 to 1.9 \\
\hline $\begin{array}{l}\text { Doctor diagnosed asthma first diagnosed } \\
\text { in } 1991 \text { or later and rated as a possible }\end{array}$ & & & & \\
\hline or probable diagnosis & $53(4)$ & $42(3)$ & $1.2 \dagger$ & 0.8 to 1.8 \\
\hline $\begin{array}{l}\text { Air flow limitation } \\
\mathrm{FEV}_{1} / \mathrm{FVC} \%<70 \%\end{array}$ & $68(6.4)$ & $93(8.4)$ & 08 & 0.5 to 1.1 \\
\hline \multicolumn{5}{|l|}{ Chronic bronchitis } \\
\hline Doctor diagnosed chronic bronchitis & $142(10.3)$ & $116(8.4)$ & 1.1 & 0.9 to 1.5 \\
\hline $\begin{array}{l}\text { Chronic obstructive bronchitis } \\
\text { Doctor diagnosed bronchitis first diagnosed }\end{array}$ & $11(1.0)$ & $13(1.1)$ & 1.0 & 0.4 to 2.3 \\
\hline $\begin{array}{l}\text { in } 1991 \text { or later and rated as a possible } \\
\text { or probable diagnosis }\end{array}$ & $47(4)$ & $27(2)$ & $1.9+$ & 1.2 to 3.1 \\
\hline \multicolumn{5}{|l|}{ Emphysema } \\
\hline Working definition of emphysema & $117(11.1)$ & $121(11.0)$ & 1.0 & 0.8 to 1.4 \\
\hline
\end{tabular}


Table 3 Lung function indices

\begin{tabular}{|c|c|c|c|c|c|}
\hline \multirow[b]{2}{*}{ Parameter } & \multicolumn{2}{|c|}{ Gulf War veterans } & \multicolumn{2}{|c|}{ Comparison group } & \multirow{2}{*}{$\begin{array}{l}\text { Adjusted difference between means* } \\
(95 \% \mathrm{Cl})\end{array}$} \\
\hline & Mean (SD) & $\%$ predicted (SD) & Mean (SD) & $\%$ predicted (SD) & \\
\hline $\mathrm{FEV}_{1}$ (I) & $4.07(0.64)$ & $98.0(13.4)$ & $4.04(0.64)$ & 97.8 (12.9) & $0.005(-0.04$ to 0.05$)$ \\
\hline FVC (I) & $5.13(0.78)$ & $101.5(12.6)$ & $5.15(0.79)$ & $102.8(12.7)$ & $-0.04(-0.09$ to 0.01$)$ \\
\hline $\mathrm{FEV}_{1} / \mathrm{FVC} \%$ & $79.6(6.0)$ & - & $78.6(5.8)$ & - & $0.7(0.2$ to 1.1$)$ \\
\hline PEFR (I/min) & $597.6(97.8)$ & 105.7 (16.3) & $598.2(93.0)$ & $106.5(15.5)$ & $0.6(-7.2$ to 8.4$)$ \\
\hline $\mathrm{FEF}_{25-75 \%}(\mathrm{l} / \mathrm{s})$ & $3.94(1.12)$ & $90.2(25.4)$ & $3.79(1.1)$ & $87.7(24.3)$ & $0.06(-0.03$ to 0.16$)$ \\
\hline $\mathrm{FEF}_{75 \%}(\mathrm{l} / \mathrm{s})$ & $1.68(0.61)$ & $78.4(27.7)$ & $1.57(0.6)$ & $74.0(25.9)$ & $0.05(0.01$ to 0.10$)$ \\
\hline
\end{tabular}

*Adjusted differences between means were obtained using robust linear regression adjusting for age, height, smoking, weight, atopy, rank, service, education, and marital status.

and respiratory conditions reported in the respiratory questionnaire using only those subjects who completed spirometric tests to ATS standards for FVC. The resulting adjusted ORs differed minimally, by 0.1 at the most. This provides reassurance that the differences in our results are not due to changes in denominators.

\section{Respiratory examination findings}

Most individual respiratory examination abnormalities and a finding of any respiratory abnormality were slightly more common in the veterans than in the comparison group and were statistically significant for wheeze on auscultation ( $1.6 \% \vee 0.6 \%$, adjusted OR 2.6 (95\% CI 1.1 to 5.9$)$ ).

\section{Respiratory exposures}

In relation to their Gulf War deployment, 783 (55.7\%) veterans reported use of respirators, $666(47.5 \%)$ reported exposure to dust storms, and $754(53.9 \%)$ reported exposure to SMOIL. SMOIL exposure was further categorised as "high" (exposed for 5 or more hours/day outside for 10 or more days) or "low" (exposed for fewer hours per day and/or for fewer days); SMOIL exposure was categorised as low for $627(44.8 \%)$ veterans and high for $127(9.1 \%)$. The timing of a veteran's deployment provided an objective measure of the likelihood of SMOIL exposure, as oil wells were set on fire after the air war had commenced on 17 January 1991. Deployment was completed before the air war by 331 veterans (23.3\%) and $1092(76.7 \%)$ were in the Gulf at or after the start of the air war.

In relation to non-Gulf War active deployments, a greater proportion of veterans than comparison group subjects had used respirators $(29.1 \% \vee 14.3 \%)$ and similar proportions reported exposure to intense smoke $(28.3 \% v 24.1 \%)$ and dust storms $(37.6 \% \vee 30.0 \%)$. During their civilian occupational history, similar proportions of veterans and comparison group subjects $(6.1 \% \vee 6.0 \%)$ reported that they had been volunteer fire fighters.

\section{Relationship between respiratory health and Gulf War exposures}

The results of Gulf War service related exposure to SMOIL and dust storms and the timing of completion of deployment in relation to the air war for the ECRHS definition suggesting asthma, $\mathrm{FEV}_{1}$, and FVC are shown in tables 4-6. These analyses were confined to veterans only.

There was a slightly increased risk of asthma according to the ECRHS definition in veterans who were in the Gulf at or after the start of the air war of borderline significance $(\mathrm{p}=0.054$, table 4$)$. Reported exposure to SMOIL was associated with a small decrease in FVC (table 6). Increasing exposure to SMOIL was associated with a decrease in FVC but not $\mathrm{FEV}_{1}$ (tables 5 and 6). The dose response slope indicated that the adjusted expected decrease in FVC per category increase in SMOIL from none to low to high was $80 \mathrm{ml}$ (table 6).

In addition to the results presented, reported exposure to SMOIL was associated with a slightly increased risk of emphysema (adjusted OR 1.7 (95\% CI 1.1 to 2.6)) and reported exposure to dust storms was associated with a slight increase in PEFR (adjusted difference between means $12.0 \mathrm{l} /$ $\min (95 \%$ CI 0.6 to 23.4$)$ ).

We also investigated associations between reported SMOIL and dust storm exposure and timing of completion of deployment in relation to the air war for doctor diagnosed asthma and bronchitis, the other lung function indices, and obstructive and restrictive ventilatory abnormalities, but there were no other significant findings.

Table 4 Relationship between ECRHS definition suggesting asthma in 1358 Gulf War veterans and SMOIL and dust storm exposure and completion of deployment before the air war

\begin{tabular}{|c|c|c|c|c|}
\hline & $\mathrm{n}$ & $\%$ & Adjusted OR† & $95 \% \mathrm{Cl}$ \\
\hline \multicolumn{5}{|l|}{ SMOIL } \\
\hline None & 56 & 9 & 1.0 & - \\
\hline Any & 81 & 11 & 1.2 & 0.8 to 1.8 \\
\hline Low & 70 & 12 & 1.3 & 0.8 to 1.9 \\
\hline High & 11 & 9 & 0.9 & 0.4 to 1.9 \\
\hline Dose response* & - & - & 1.1 & 0.8 to 1.4 \\
\hline \multicolumn{5}{|l|}{ Dust storms } \\
\hline No & 63 & 9 & 1.0 & - \\
\hline Yes & 77 & 12 & 1.1 & 0.8 to 1.7 \\
\hline \multicolumn{5}{|c|}{ Deployment completed before air war } \\
\hline Yes & 22 & 7 & 1.0 & - \\
\hline No & 119 & 11 & 1.7 & 1.0 to 2.9 \\
\hline
\end{tabular}

*Dose response is the expected increase in the odds ratio per category increase in SMOIL exposure. †Odds ratios adjusted for age, height, weight, atopic status, smoking, service type, rank, education, and marital status. 


\begin{tabular}{|c|c|c|c|c|}
\hline & Mean & SD & $\begin{array}{l}\text { Adjusted difference } \\
\text { between means } †\end{array}$ & $95 \% \mathrm{Cl}$ \\
\hline \multicolumn{5}{|l|}{ SMOIL } \\
\hline None & 4.09 & 0.64 & 0.0 & - \\
\hline Any & 4.05 & 0.64 & -0.05 & -0.11 to 0.01 \\
\hline Low & 4.06 & 0.66 & -0.05 & -0.11 to 0.02 \\
\hline High & 4.04 & 0.60 & -0.03 & -0.15 to 0.08 \\
\hline Dose response* & - & - & -0.03 & -0.08 to 0.02 \\
\hline \multicolumn{5}{|l|}{ Dust storms } \\
\hline No & 4.08 & 0.60 & 0.0 & - \\
\hline Yes & 4.06 & 0.65 & -0.03 & -0.09 to 0.03 \\
\hline \multicolumn{5}{|c|}{ Deployment completed before air war } \\
\hline Yes & 4.08 & 0.67 & 0.0 & - \\
\hline No & 4.07 & 0.63 & -0.06 & -0.13 to 0.01 \\
\hline
\end{tabular}

\section{Assessment of possible participation bias}

The telephone survey for non-participants upon which part of the prediction model for assessing possible participation bias was based was completed by approximately one quarter $(\mathrm{n}=411)$ of all study non-participants. The prediction model assumed that the telephone respondents' answers were representative of those of the remainder of the nonparticipants.

The predicted "full participation" age, rank, and service adjusted OR of differences in the prevalence of doctor diagnosed asthma between veterans and the comparison group was 1.14 , which is only marginally lower than the corresponding OR of 1.15 observed for participants.

\section{DISCUSSION}

Australian veterans of the 1991 Gulf War reported more respiratory symptoms, more asthma according to the ECRHS definition but not other definitions, and more doctor diagnosed bronchitis that had first been diagnosed since the Gulf War than did the randomly sampled military comparison group. Veterans were found to have more wheeze on examination. Lung function was similar between groups. Veterans had a slightly higher late flow $\left(\mathrm{FEF}_{75 \%}\right)$, suggesting better small airways function. Even though this difference was statistically significant, it was small and probably clinically unimportant. Any effects of exposures such as
SMOIL or dust storms were not reflected in reductions to $\mathrm{FEF}_{25-75 \%}, \mathrm{FEF}_{75 \%}$, or $\mathrm{FEV}_{1}$ that would be consistent with a picture of greater airflow limitation in veterans.

Our findings with respect to asthma were not consistent. While more veterans reported a condition suggesting asthma according to the ECRHS definition, ${ }^{18}$ fewer participants overall demonstrated airflow limitation or an obstructive ventilatory abnormality on spirometry, and the proportions did not differ between the study groups. Asthma is characterised by variable airflow obstruction, and the proportions based on $\mathrm{FEV}_{1} / \mathrm{FVC}<70 \%$ relate to respiratory function at the time of the medical assessment. Although the absolute proportions defined as having asthma differed according to the definitions used, the relative proportions of the two study groups who had asthma were similar. The finding of increased wheeze on examination of the veterans is consistent with their greater use of asthma medications, but not with the finding of better small airways function. There was no obvious explanation for the differences in symptom reporting between study groups across service types or rank, and these may have been chance or isolated findings.

One of the strengths of our study was collecting data on self-reported exposure to SMOIL and dust storms and exploring the relationship between these exposures and respiratory health outcomes. The similarity between study groups for non-Gulf War exposures to dust storms and

Table 6 Relationship between mean forced vital capacity (FVC) of 1083 Gulf War veterans and SMOIL and dust storm exposure and completion of deployment before the air war

\begin{tabular}{lllll}
\hline & Mean & SD & $\begin{array}{l}\text { Adjusted difference } \\
\text { between meanst }\end{array}$ & 95\% Cl \\
\hline SMOIL & & & & - \\
None & 5.17 & 0.77 & 0.0 & -0.18 to -0.03 \\
$\quad \begin{array}{l}\text { Any } \\
\text { Low }\end{array}$ & 5.10 & 0.79 & -0.10 & -0.16 to 0.004 \\
$\quad \begin{array}{l}\text { High } \\
\text { Dose response* }\end{array}$ & 5.11 & 0.81 & -0.08 & -0.28 to 0.003 \\
$\begin{array}{l}\text { Dust storms } \\
\text { No }\end{array}$ & 5.03 & 0.66 & -0.14 & -0.14 to -0.02 \\
$\quad$ Yes & - & - & -0.08 & - \\
$\begin{array}{l}\text { Deployment completed before air war } \\
\text { Yes }\end{array}$ & 5.16 & 0.77 & 0.0 & -0.12 to 0.02 \\
No & 5.10 & 0.80 & -0.05 & - \\
\hline
\end{tabular}

*Dose response is the expected change in FVC per category increase in SMOIL exposure. tDifference between means adjusted for age, height, weight, atopic status, smoking, service type, rank, education, and marital status. 
intense smoke and fire fighting suggests that non-Gulf War respiratory exposures, including occupational exposures, are not likely to explain the increase in respiratory symptoms reported by veterans. A greater proportion of US and UK veterans reported SMOIL exposure $(61-96 \%)^{10} 32$ than did Australian veterans (53.9\%). The majority of Australian veterans were naval personnel and were less likely to be exposed to SMOIL than the predominantly land based troops of the US and UK forces.

Veterans who reported exposure to SMOIL had an increased risk of emphysema, according to the working definition used in the study, than veterans who did not report exposure. A dose-response relationship was evident for FVC and reported exposure to SMOIL, but the small differences found were not considered to be clinically important. Typically, emphysema affects $\mathrm{FEV}_{1}$ more than FVC, so these findings are inconsistent. When we analysed respiratory outcomes on the basis of being in the Gulf at or after the commencement of the air war, the only association was with ECRHS defined asthma, and this was of borderline significance. Veterans who reported exposure to dust storms actually had a slightly better PEFR than veterans who did not report exposure, but the difference was also small and not clinically important.

The use of different definitions for respiratory conditions in the different studies can make comparisons difficult. Our finding of increased respiratory symptom reporting and of bronchitis first diagnosed since the Gulf War in veterans supports the findings of previous cross sectional studies. ${ }^{10-12} 16$ In addition, our finding that more veterans report asthma is consistent with an increased reporting of asthma in veterans from Iowa ${ }^{10}$ and the UK, ${ }^{12}$ but not with the similar rates of asthma reported by a broader population of US veterans. ${ }^{11}$

Many of the conclusions of other epidemiological studies of veterans' respiratory health have been based solely on selfreported findings of postal or telephone questionnaire surveys. The use of spirometric tests in our study has provided objective data. Only two previous cross sectional studies have undertaken lung function testing. Neither Danish veterans, predominantly involved in humanitarian and peacekeeping duties after the war had ended, ${ }^{15}$ nor US Navy Reserve Unit construction workers ${ }^{14}$ had significantly different lung function to their non-Gulf comparison groups.

Modelled exposure to SMOIL and US troop movements have been integrated to assess the association of SMOIL with respiratory health. ${ }^{33-35}$ Odds ratios for self-reported asthma and bronchitis increased with increasing self-reported, but not modelled, SMOIL exposure in Iowa veterans. ${ }^{33}$ Physician diagnosed asthma in participants in a clinical evaluation programme was associated with cumulative SMOIL exposure and days exposed to high levels in a dose-response relationship. ${ }^{34}$ No increased risk of post-war respiratory admissions to hospital was found in US veterans with increasing levels of exposure. ${ }^{35}$

Our study has a number of strengths including the use of objective measures of health and of exposure assessment where possible, and a recognised approach for comparing groups using various definitions. ${ }^{36}$ A further strength is the use of a randomly sampled military comparison group.

We used ATS criteria for standardising the performance and evaluation of spirometric parameters. ${ }^{21}$ The ATS criteria were primarily developed for clinical settings but their application has been extended to epidemiological studies. Despite our measures to standardise spirometric performance, the proportions in our study who did not meet the ATS criteria were a little higher than those found in other studies involving multiple centres or repeated measurements over time in which test failures of $8.9-13.8 \%$ (as measured by criteria that varied but included a measure of $\mathrm{FEV}_{1}$ reproducibility) were reported..$^{37-39}$ The proportion of the study groups who fulfilled the ATS criteria was slightly lower in the veteran group and is of some concern because it could reflect a higher prevalence of respiratory disease in veterans. $^{37-39}$

Despite a rigorous and extended contact and recruitment strategy applied to both study groups, the participation rate in our comparison group was lower than that of the veteran group but was comparable to that of other major postal surveys of veterans. ${ }^{11}{ }^{12}{ }^{15}$ The differential participation rates highlight the difficulties faced by researchers in contacting and recruiting young, highly mobile, military populations. Few studies have formally evaluated participation bias in published papers. Our finding of very similar "full participation" predicted and observed odds ratios for doctor diagnosed asthma suggest that participation bias is unlikely to explain the differences (or lack thereof) in respiratory health status found between our study groups.

We adjusted for potential confounding factors including smoking, atopy, height and weight that were known to increase the risk of respiratory disease or affect lung function. It is possible that other unidentified confounding factors, such as work exposures, may have had an impact on the results. Information bias may have affected our results as veterans may be more susceptible to media influences on self-reporting of respiratory symptoms or conditions. This source of bias would not have affected the results of objective measures such as those based on spirometry.

Recall bias ${ }^{40}$ may have occurred, as those who experienced respiratory symptoms may also be more likely to report exposures such as SMOIL and dust storms. ${ }^{41}$ Veterans who were exposed might also be more likely to associate their symptoms with exposure than those who were not. Worsening self-perception of health (though not worsening physical health) over time in UK Gulf War veterans has been associated with increased reporting of Gulf War exposures. ${ }^{42}$ Completion of deployment before the air war would not be subject to such biases in our study. Assessment of exposure to SMOIL and dust storms in our study was based on selfreports. SMOIL was a reliably recalled exposure, assessed using kappa $(\kappa)$ as a measure of agreement ${ }^{43}$ over time in both UK $(\kappa=0.79)^{42}$ and US $(\kappa=0.69)^{44}$ Gulf War veterans. This suggests that recall bias would have had minimal impact on the reporting of SMOIL over time and on the association between reported SMOIL exposure and respiratory health outcomes.

In summary, our use of a respiratory examination and spirometric testing to compare study groups, in addition to self-reported respiratory outcomes, increased the comprehensiveness and objectivity of our assessment over the limited previous research on this subject. Veterans reported more respiratory symptoms, more asthma according to one definition, and more bronchitis first diagnosed since the Gulf War. However, veterans did not have poorer lung function than the comparison group, and any effects of exposures such as SMOIL or dust storms were not reflected in greater airflow limitation. Our findings do not suggest major long term sequelae of exposure to oil fire smoke or dust storms.

\section{ACKNOWLEDGEMENTS}

This study was overseen by a Scientific Advisory Committee and by a Veterans' Consultative Forum, and the authors are grateful to members for their contributions and support. They also acknowledge the contribution of Health Services Australia who conducted the medical assessments and thank Associate Professor David Johns and Ms Eleonora Side for their assistance in the spirometric training for nurses, and Dr Keith Horsley, Dr Warren Harrex, Mr Bob Connolly and his contact and recruitment team at the Department of Veterans' Affairs. 


\section{Authors' affiliations}

H L Kelsall, M R Sim, A B Forbes, D P McKenzie, D C Glass, J F Ikin, P Ittak, M J Abramson, Department of Epidemiology and Preventive Medicine, Monash University, Melbourne, Victoria 3004, Australia

This study was funded by the Australian Government Department of Veterans' Affairs.

\section{REFERENCES}

1 Tawfiq NI. Response by Saudi Arabia to the environmental crisis caused by the Gulf War. In: Al-Shatti AKS, Harrington JM, eds. The environmental and health impact of the Kuwaiti oil fires. Proceedings of an international symposium, 17 October 1991. Birmingham, UK: University of Birmingham, 1992:40-3

2 Hobbs P, Radke L. Airborne studies of the smoke from the Kuwait oil fires. Science 1992;256:987-91.

3 Cofer III WR, Stevens RK, Winstead EL, et al. Kuwaiti oil fires: compositions of source smoke. J Geophys Res 1992;97:14, 521-5.

4 US Department of Defense. Environmental exposure report: oil well fires. Washington, D.C.: US Department of Defense, 2000.

5 Osman Y. Environmental surveys conducted in the Gulf region following the Gulf War to identify possible neurobehavioral consequences. Environ Res 1997;73:207-10.

6 US Department of Defense. Environmental exposure report: particulate matter. Washington, D.C.: US Department of Defense, 2000.

7 Hyams KC, Hanson K, Wignall FS, et al. The impact of infectious diseases on the health of U.S. troops deployed to the Persian Gulf during Operations Desert Shield and Desert Storm. Clin Infect Dis 1995;20:1497-504.

8 Richards AL, Hyams KC, Watts DM, et al. Respiratory disease among military personnel in Saudi Arabia during Operation Desert Shield. Am J Public Health 1993;83:1326-9

9 Petruccelli BP, Goldenbaum M, Scott B, et al. Health effects of the 1991 Kuwait oil fires: a survey of US army troops. J Occup Environ Med 1999:41:433-9.

10 The lowa Persian Gulf Study Group. Self-reported illness and health status among Gulf War veterans: a population-based study. JAMA 1997;277:238-45.

11 Kang HK, Mahan CM, Lee KY, et al. Illnesses among United States veterans of the Gulf War: a population-based survey of 30,000 veterans. J Occup Environ Med 2000;42:491-501.

12 Unwin C, Blatchley N, Coker W, et al. Health of UK servicemen who served in Persian Gulf War. Lancet 1999:353:169-78.

13 Lee HA, Gabriel R, Bolton JPG, et al. Health status and clinical diagnoses of 3000 UK Gulf War veterans. J R Soc Med 2002;95:491-7.

14 Gray GC, Kaiser KS, Hawksworth AW, et al. Increased postwar symptoms and psychological morbidity among U.S. Navy Gulf War veterans. Am J Trop Med Hyg 1999:60:758-66.

15 Ishoy T, Suadicani P, Guldager B, et al. State of health after deployment in the Persian Gulf. The Danish Gulf War Study. Dan Med Bull 1999;46:416-9.

16 Cherry N, Creed F, Silman A, et al. Health and exposures of United Kingdom Gulf war veterans. Part I: The pattern and extent of ill health. Occup Environ Med 2001;58:291-8.

17 Ikin JF, Sim MR, Creamer MC, et al. War-related psychological stressors and risk of psychological disorders in Australian veterans of the 1991 Gulf War. Br J Psychiatry 2004; 185: 116-26.

18 Burney PGJ, Luczynska C, Chinn S, et al. The European Community Respiratory Health Survey. Eur Respir J 1994;7:954-60.

19 Ferris BG. Epidemiology standardization project. Am Rev Respir Dis 1978;118:1-120.

20 Flint A, Howell H, Crapo RO, et al. QRS SpiroCard and QRS SpirOxCard test report. Salt Lake City, Utah: LDS Hospital, 2000.
21 American Thoracic Society. Standardization of spirometry: 1994 update. Am J Respir Crit Care Med 1995; 152:1107-36.

22 Global Initiative for Chronic Obstructive Lung Disease. Global strategy for the diagnosis, management and prevention of chronic obstructive disease. NHLB/ WHO Workshop Report: NHLB/WHO, 2001.

23 Ciba Guest Symposium Report. Terminology, definitions, and classification of chronic pulmonary emphysema and related conditions. Thorax 1959; 14:286-99

24 Hordle DA, Mehta V, Tomensen B, et al. Development of the skin prick test for allergen assay. J Immunol Methods 1984;75:369-82.

25 American Thoracic Society. Lung function testing: selection of reference values and interpretative strategies. Am Rev Respir Dis 1991;144:1202-18.

26 Stata Corporation. Stata Statistical Software Version 7. College Station, Texas: Stata Corporation, 2001.

27 Quanjer PH, Tammeling GJ, Cotes JE, et al. Lung volumes and forced ventilatory flows. Report Working Party. Standardization of lung function tests. European Community for Steel and Coal. Official Statement of the European Respiratory Society. Eur Respir J 1993;6:5-40

28 Knudson RJ, Lebowitz MD, Holberg CJ, et al. Changes in the normal maximal expiratory flow-volume curve with growth and aging. Am Rev Respir Dis 1983;127:725-34.

29 Rousseeuw PJ, Leroy AM. Robust regression and outlier detection, 2nd ed. Hoboken, NJ: Wiley, 2003.

30 Ware JE, Kosinski M, Keller SD. A 12-item Short-Form Health Survey. Construction of scales and preliminary tests of reliability and validity. Med Care 1996;34:220-33.

31 Ware JE, Kosinski MA, Keller SD. SF-12: How to score the SF-12 physical and mental health summary scales, 3rd ed. Lincoln, Rhode Island: Quality Metric Incorporated, 1998

32 Cherry N, Creed F, Silman A, et al. Health and exposures of United Kingdom Gulf war veterans. Part II: The relation of health to exposure. Occup Environ Med 2001;58:299-306

33 Lange JL, Schwartz DA, Doebbeling BN, et al. Exposures to the Kuwait oil fires and their association with asthma and bronchitis among Gulf War veterans. Environ Health Perspect 2002;110:1141-6.

34 Cowan DN, Lange JL, Heller J, et al. A case-control study of asthma among U.S. Army Gulf War veterans and modeled exposure to oil well fire smoke. Mil Med 2002; 167:777-82.

35 Smith TC, Heller JM, Hooper TI, et al. Are Gulf War veterans experiencing illness due to exposure to smoke from Kuwaiti oil well fires? Examination of Department of Defense hospitalization data. Am J Epidemiol 2002;155:908-17.

36 Pekkanen J, Pearce N. Defining asthma in epidemiological studies. Eur Respir J 1999;14:951-7.

37 Eisen EA, Oliver LC, Christiani DC, et al. Effects of spirometry standards in two occupational cohorts. Am Rev Respir Dis 1985;132:120-4

38 Eisen EA, Robins JM, Greaves IA, et al. Selection effects of repeatability criteria applied to lung spirometry. Am J Epidemiol 1984;120:734-42.

39 Eisen EA, Dockery DW, Speizer FE, et al. The association between health status and the performance of excessively variable spirometry tests in a population based-study in six US cities. Am Rev Respir Dis 1987;136:1371-6.

40 Rothman KJ, Greenland S. Modern epidemiology, 2nd ed. Philadelphia, PA: Lippincott-Raven, 1998.

41 Checkoway H, Pearce N, Kriebel D. Research methods in occupational epidemiology, 2nd ed. New York: Oxford University Press, 2004.

42 Wessely S, Unwin C, Hotopf $M$, et al. Stability of recall of military hazards over time: evidence from the Persian Gulf War of 1991. Br J Psychiatry 2003;183:314-22

43 Cohen J. A coefficient of agreement for nominal scales. Educ Psychol Measure 1960;20:37-46.

44 McCauley LA, Joos SK, Spencer PS, et al. Strategies to assess validity of selfreported exposures during the Persian Gulf War. Environ Res 1999;81:195-205. 